\title{
Student Questions in Solving Open-Ended Mathematics Problems
}

\author{
Mohamad Aminudin ${ }^{1}$, Hevy Riski Maharani ${ }^{2}$, Fatimah Candrawati Dewi ${ }^{3}$ \\ Universitas Islam Sultan Agung, Semarang, Indonesia ${ }^{1,2,3}$ \\ \{aminudin@unissula.ac.id ${ }^{1}$, hevyrisqi@unissula.ac.id ${ }^{2}$, fatimahcandra1@gmail.com³ \}
}

\begin{abstract}
Humans are commanded by God to think in order to get the truth and avoid being misled. Asking is part of thinking, so that to solve math problems students are required to ask quality questions. This case study research aims to explore students' questions when solving open-ended mathematical problems. This case study involved three junior high school students who could provide more than one solution. Mathematical tests and unstructured interviews were used to collect data. The results showed that there were three types of questions that were in students' minds while solving open-ended mathematical problems, including investigative questions, data collection tool questions, and validation questions.
\end{abstract}

Keywords: Questions, Problem Solving, Open-ended Problems

\section{Introduction}

Being able to solve problems well has been the main goal in learning mathematics since ancient times until now [1]-[3]. The various stages of problem solving are initiated by experts. Polya provides four stages of problem solving which are widely used by teachers and students in solving math problems [4]. Posamentier \& Krulik provide strategies that are seen as efficient in solving mathematical problems [5],[6]. However, when one looks at the idea of how mathematical problems are solved, he has not examined the role of the questions posed in the problem.

In surah Al An' am verse 50, Allah SWT commands people to think in order to get the truth and avoid error [7]. In addition, to build knowledge, a person needs to ask and ask is a divine command in surah An ahl verse 43 [8]. Usually, someone will think when they have a complex problem. A problem means something that needs examination or resolution [9]. The type of problem that is often encountered is an open-ended problem. Open-ended problems are widely used in various countries to improve thinking skills [10]. According to Foong, openended problems provide students the opportunity to demonstrate mathematical knowledge, skills, and understanding [10]. Therefore, open-ended problems must challenge students to reason and think, and require students to apply various approaches and strategies.

Asking questions is a cognitive activity that is very important in solving problems [11], [12]. Asking questions should be a serious concern for students in solving problems. In fact, Polya in each stage of problem solving asked what questions could help solve each stage of problem solving [4]. In addition, Strachan initiated several questions in the learning process 
in the form of questions about making assumptions about the topics or problems at hand, questions about understanding interests and power relationships, questions to explore alternative ways of acting, and questions about making ethical choices [13]. Wallace \& Jefferson provide four question criteria, namely regarding topic, class, description, and relevance [14]. Thus, the right form of questions is the key to successful solving of mathematical problems.

Previous studies have shown the important role of questions posed by teachers in learning mathematics in the classroom [15]-[20]. The questions asked by the teacher depend on the teacher's teaching style [15]. Students provide longer answers to open-ended problems when the teacher asks "how?" and "why?" [19]. These studies show the very important questions teachers ask during mathematics learning. To improve thinking skills, students need to have the urge to ask questions. In fact, maybe as long as students think to solve math problems independently, students ask questions in their mind. So, every student needs to be a good questioner in solving problems. Therefore, the aim of this study is to explore students' questions while solving open-ended problems.

\section{Research Method}

This study explored the problem and developed a detailed understanding of unique and occurring phenomena. Therefore, this study used a qualitative research design with a case study approach [21]. This study focuses on the characteristics of students' questions posed in their minds while solving open-ended mathematical problems. The subjects of this study were students who were able to solve open-ended math problems. Subjects could provide more than one answer for the area of the quadrilaterals, and are also communicative in the interview process. The researcher took three subjects, including a student who answered with two solutions, a student who answered with three solutions, and a student who answered with four solutions.

The research instruments included tests and interviews. The test was in the form of an open-ended mathematical problem, in the form of "Given the rectangle with a size of $8 \mathrm{~cm}$ and $5 \mathrm{~cm}$, determine the area of the rectangle!". This problem adopted an open-ended problem as exemplified by [10]. Students were asked to work with a duration of about 30 minutes. Then, students were directly interviewed to get thought process data that focused on any questions that were on the student's mind while doing the test. The unstructured interview type was used in this study.

After the research data were obtained in the form of student answers and recorded interviews, then the data were analyzed to get a conclusion. The stages of data analysis in this study began by copying the data from the recorded interviews from audio to written form. Then, reduce the data by focusing on the questions that were in students' minds while solving open-ended mathematical problems. After the data were reduced, the data were coded and categorized based on the stages of problem solving. The final stage was to make conclusions on the characteristics of the questions generated by students.

\section{Result and Discussion}

The results of the analysis of students' answers in solving open-ended problems found three subjects, including the 1st subject with the initials LMN which provided two solutions, 
the 2nd subject with the initials AA provided three solutions, and the 3rd subject with the initials NA provided four solutions to the area of a rectangle. The results of the interview of the three subjects showed that there were questions in the subject's mind when solving the questions.

\subsection{The First Subject}

The first subject with the initials LMN. The subject gave two answers for the area of the quadrilateral, namely $24 \mathrm{~cm}^{2}$ and $40 \mathrm{~cm}^{2}$. The first question that showed in the subject's mind during the process of understanding the problem were "What kind of shape was it? Was it a parallelogram or something else?" The subject tried to identify a rectangular shape that met the criteria for the problem. Then, the subject focused on the size of the rectangle. So that the subject asked himself, "Did you think if the size is two and different, it was means that the rectangle was a rectangle and a parallelogram?". After the subject decided that the appropriate rectangle shape was a rectangle and a parallelogram, the next question arose. "What were formula the area of the rectangle and parallelogram? Then if the height of the parallelogram was not known, then did I have to find the height first?". This question invoked a schematic regarding the formula for the area of a rectangle and a parallelogram, and the height of a parallelogram. Furthermore, the subject substituted the known size in the formula for area of the rectangle and parallelogram. Since the area of the two shapes was obtained, then the question arose to the subject, namely "did my answer correct? May be it could be wrong?". Figure 1 below is the subject's answer to the open-ended problem which is given with two solutions.

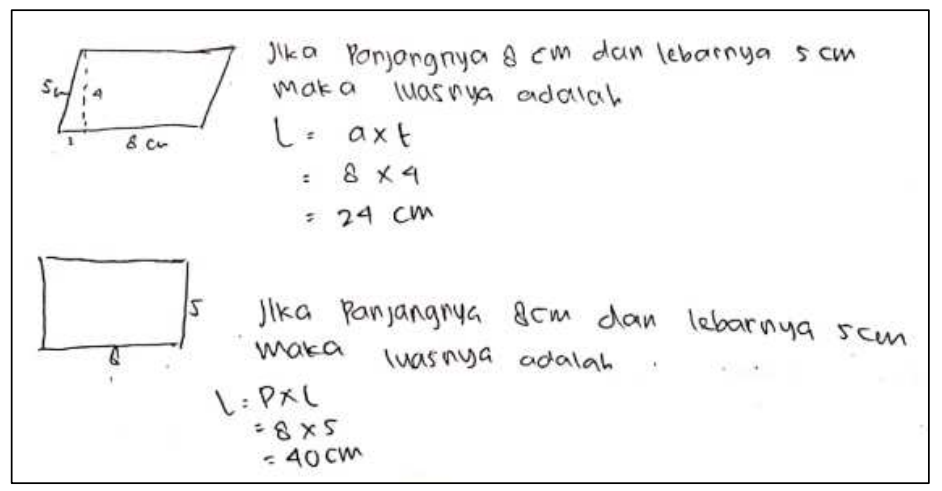

Fig. 1. Written Answers to the LMN subject

\subsection{The Second Subject}

The second subject with the initials AA. The subject gave three answers to the area of the quadrilateral, namely $40 \mathrm{~cm}^{2}, 20 \mathrm{~cm}^{2}$, and $40 \mathrm{~cm}^{2}$. The first question in the subject's mind while understanding the question were "what was the shape of the rectangle?" and " how many squares could be formed?". This question existed due to the subject's confusion in determining the exact shape of the quadrilateral on the problem. The next question was the size of the rectangle. This question the subject raised in his mind. Because the subject argued that the area of a quadrilateral depended on a clearly known size. If the area was rectangular, then the length and width of the side of the rectangle must be clearly known. If the area was 
the rhombus, then the length of the diagonals needed to be clearly identified. However, the subject decides on the quadrilateral in question, namely the rectangle, parallelogram, and rhombus.

Then the subject asked himself about the formula for obtaining the area of the three shapes. When the subject had obtained the formula for the area of a rectangle, a parallelogram, and a rhombus, then substituted the size of the rectangle for the three shapes, and finally got the area of the quadrilateral, the subject asked himself, "did the formula correct or not correct?". This question was a form of doubt by the subject on the formula for the area of the given quadrilateral. The subject also asked whether there was a possibility of another quadrilateral shape such as a trapezoid. However, the subject argued that if it was trapezoid, then the size of the unknown would be the height of the trapezoid. The subject felt confident in the answer. The subject did not double-check the answer. Figure 2 below is the subject's answer to the open-ended problem which is given with three solutions.

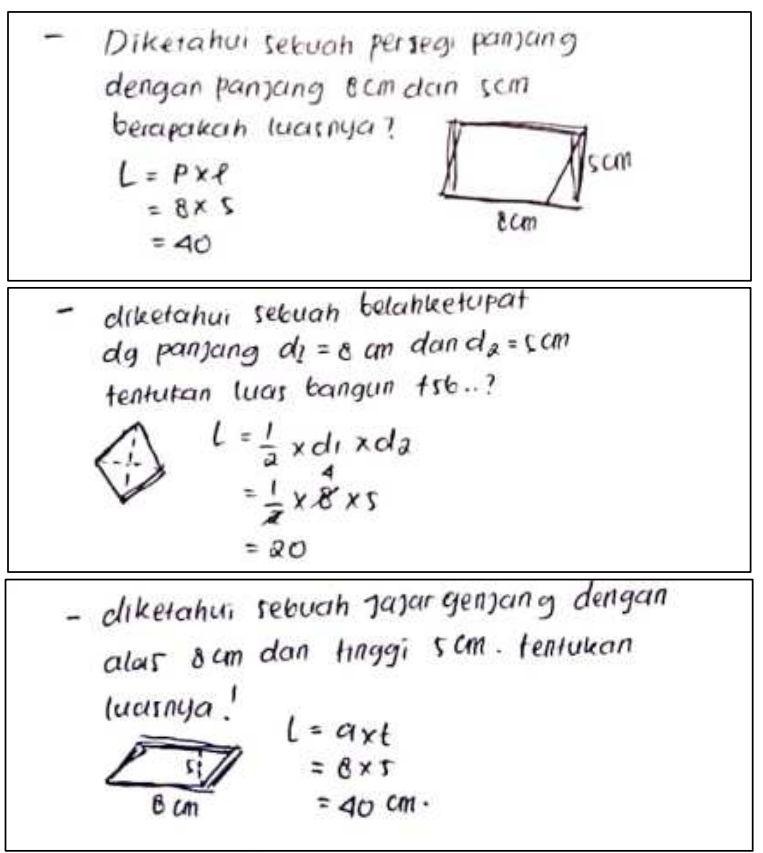

Fig. 2. Written Answers to the Subject AA

\subsection{The Third Subject}

The third subject with the initials NA. The subject gave four answers to the area of the quadrilateral, namely $20 \mathrm{~cm}^{2}, 40 \mathrm{~cm}^{2}, 40 \mathrm{~cm}^{2}$, and $20 \mathrm{~cm}^{2}$. The first question that came to the subject's mind after reading the question many times was "what is the shape of a rectangle? And what size is it?". Next, the subject decided to try all the quadrilateral. Then, the subject chose the quadrilateral that matches the data known in the problem. The subject decided that the square and trapezoid are not the quadrilateral in question. The square was not a quadrilateral in the problem, because two different sizes are known in the problem. According to the subject, the trapezoid is not a rectangle in the problem, because to find the area of the 
trapezoid, the height of the trapezoid is needed. Finally, the subject chose a quadrilateral shape which may include a rectangle, a parallelogram, a rhombus, and a kite.

The next step, the subject determined the initial size of the quadrilateral on the problem. The two measurements in the problem were the length and width for the rectangle, and the length of the diagonals for the rhombus and kite. Then the subject determined the formula for the area of a rectangle, parallelogram, rhombus, and kite. The specified size was substituted in the formula for the area of the given rectangle. After the subject got the area of the specified rectangle shape, then the subject checked the area again. The subject asked himself "was there an error in my answer?". Figure 3 below is the answer to the NA subject to the open-ended problem with four solutions.

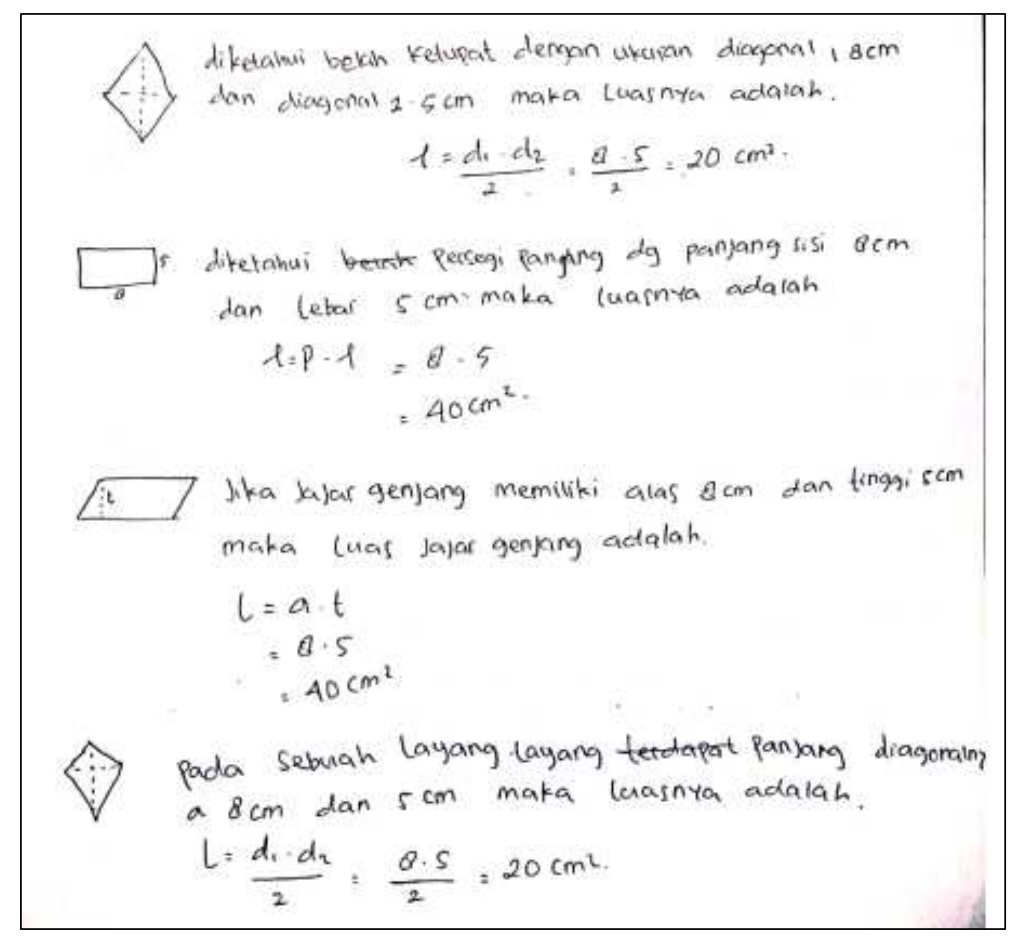

Fig. 3. Written Answer of Subject AA

From the questions that were in the minds of the three subjects when solving open-ended mathematical problems, it can be summarized that are adapted to the stages of Polya [4], in table 1 .

Table 1. Characteristics of Subject Questions

\begin{tabular}{|c|c|}
\hline Polya's stages & Question characteristics \\
\hline Understanding the problem & $\begin{array}{l}\text { a. Identifying the shapes of the quadrilateral } \\
\text { b. Make predictions about the shape of a specific quadrilateral based } \\
\text { on the known size properties of the problem } \\
\text { c. Determine the unknown height of the parallelogram on the problem }\end{array}$ \\
\hline Devising a plan & $\begin{array}{l}\text { a. Define the formula for the area of the claimed quadrilateral } \\
\text { b. Determine the correctness of the memorable area formula. }\end{array}$ \\
\hline Carrying out the plan & No questions asked. \\
\hline Looking back & Check the correctness of the answers \\
\hline
\end{tabular}


The results showed that during the process of solving open-ended mathematical problems, the three subjects asked questions in the subject's mind. The stages of solving open-ended mathematical problems can be divided into four stages of solving [4] problems, including understanding the problem, devising a plan, carrying out the plan, and looking back. When understanding open-ended mathematical problems, the subject's questions are related to identifying the rectangular shapes that exist in the subject's memory, making guesses about the special shape of the rectangle that corresponds to the size known in the problem, and the question of the length of the trapezium, because there is no measurement to the problem. Questions at this stage could be referred to as investigative questions. Through this questioning, the subject carefully examines the specific form of the universal form, then makes conjectures and claims based on known data.

At the devising a plan stage, the subjects already knew that in order to get the area of the quadrilateral that were claimed, the area formula was needed. The area of the plane that was claimed to be obtained by substituting the dimensions of the shape. Therefore, the characteristic of the question that arose in the mind of the subject were to determine the area formula of the claimed rectangle and the correctness of the area formula specified. Questions at this stage could be referred to as "data collection tools" questions. This question encouraged the subject to remember the right formula that could be use based on the claimed data so that what they were looking for can be found.

At the carrying out the plan stage, the subject does not raise any questions in his mind. The subject is sure that what each stage of the calculation is doing is correct. At the looking back stage, ask himself about the truth in terms of the area of the quadrilateral obtained. This question motivates the subject to examine each stage of the calculation until the area value of the quadrilateral is obtained. Therefore, the characteristic of questions that arise in the mind of the subject is to test the correctness of the answer. Questions at the looking back stage can be referred to as validation questions. This question moves the subject to test the correctness of the final answer or the entire answer made.

The questions posed in the mind of the subject were basically the subject's attempt to engage and solve open-ended mathematical problems. In line with the research results of Ley et.al that the type of question greatly affects the level of student involvement in solving math problems [22]. The two types of questions were procedural questions and conceptual questions. Procedural questions were related to the fluency of students using procedural knowledge, while conceptual questions were related to how students remember and build understanding of new concepts to be used in solving problems. In Browne \& Keely provide an idea of what questions students need to ask when solving problems, including what is the problem? What words are ambiguous about the problem? Are there any assumptions needed to solve the problem? Was there an error while troubleshooting? What is the conclusion of the solution obtained? [23],[24].

\section{Conclusion}

There were three types of questions that arose in students' minds while solving open-ended mathematical problems, including investigative questions, data collection tool questions, and validation questions. Investigative questions arose when understanding a problem, data collection tool questions arise when devising a plan, and validation questions arise when reviewing the final answer or overall answer. The results showed that the characteristics of the questions in students' minds would affect thinking skills in solving open-ended problems. 


\section{Acknowledgments}

Researchers would like to thank LPPM Unissula Semarang for funding this research.

\section{References}

[1] S. E. Sigurdson, A. T. Olson, and R. Mason, "Problem solving and mathematics learning," J. Math. Behav., vol. 13, no. 4, pp. 361-388, 1994, doi: 10.1016/07323123(94)90001-9.

[2] N. M. Aljaberi and E. Gheith, "Pre-Service Class Teacher' Ability in Solving Mathematical Problems and Skills in Solving Daily Problems," High. Educ. Stud., vol. 6, no. 3, p. 32, 2016, doi: 10.5539/hes.v6n3p32.

[3] M. M. Capraro, S. A. An, T. Ma, A. F. Rangel-Chavez, and A. Harbaugh, "An investigation of preservice teachers' use of guess and check in solving a semi openended mathematics problem," J. Math. Behav., vol. 31, no. 1, pp. 105-116, 2012, doi: 10.1016/j.jmathb.2011.10.002.

[4] G. Polya, How to Solve It, 2nd ed. New Jersey: Princeton university Press, 1973.

[5] A. S. Posamentier and S. Krulik, Problem Solving in Mathematics Grade 3-6: Powerfull Strategies to Deepen Understanding. United States of America: Corwin A SAGE Company, 2009.

[6] A. S. Posamentier and S. Krulik, Problem-solving strategies for efficient and elegant solutions_a resource for the mathematics teacher. California: Corwin Press, Inc, 1998.

[7] T. Hidayat, A. Abdussalam, and F. Fahrudin, "Konsep Berpikir (Al-Fikr) Dalam Alquran dan Implikasinya Terhadap Pembelajaran PAI di Sekolah (Studi Tematik tentang Ayat-ayat yang Mengandung Term al-Fikr)," TARBAWY Indones. J. Islam. Educ., vol. 3, no. 1, p. 1, 2016, doi: 10.17509/t.v3i1.3455.

[8] Mainizar, "Penggunaan Kata Tanya/ Istifhanah dalam Alqur'an," in Materi Pokok Qur'an Hadist II, Jakarta: Dirjen Pembinaan Kelembagaan Agama Islam Universitas Terbuka, 1997, p. 17.

[9] J. David H, Learning to Solve Problems: A Handsbook for Designing ProblemsSolving Learning Environments. New York USA: Routledge: Taylor \& Francis Group, 2011.

[10] P. Y. Foong, "Open-ended Problems for Higher-Order Thinking in Mathematics," Teach. Learn., vol. 20, no. 2, pp. 49-57, 2000, [Online]. Available: http://repository.nie.edu.sg/jspui/bitstream/10497/365/1/TL-20-2-49.pdf, tgl 15 Nov 2013.

[11] V. Cojocariu and C. Butnaru, "Asking questions - critical thinking tools," Procedia Soc. Behav. Sci., vol. 128, pp. 22-28, 2014, doi: 10.1016/j.sbspro.2014.03.112.

[12] P. A. Ertmer, A. Sadaf, and D. Ertmer, "Designing Effective Question Prompts to Facilitate Critical Thinking in Online Discussions," Des. Princ. Pract. An Int. J., vol. 5, no. 4, 2011, doi: 10.18848/1833-1874/CGP/v05i04/38121.

[13] D. Strachan, Making Question Work: A Guide to What and How to Ask for Facilitators, Consultants, Managers, Coaches, and Educators, 1st ed. United States of America: Jossey-Bass, 2007.

[14] E. D. Wallace and R. N. Jefferson, "Developing critical thinking skills: Assessing the effectiveness of workbook exercises," J. Coll. Teach. Learn., vol. 12, no. 2, pp. 101$109,2015$.

[15] E. Aizikovitsh-Udi and J. Star, "The skill of asking good questions in mathematics 
teaching," Procedia - Soc. Behav. Sci., vol. 15, pp. 1354-1358, 2011, doi: 10.1016/j.sbspro.2011.03.291.

[16] S. Masitah, "Review of Effective Teacher Questioning in Mathematics Classrooms," Int. J. Humanit. Soc. Sci., vol. 3, no. 17, pp. 224-231, 2013.

[17] B. Purdum-Cassidy, S. Nesmith, R. D. Meyer, and S. Cooper, "What are they asking? An analysis of the questions planned by prospective teachers when integrating literature in mathematics," J. Math. Teach. Educ., vol. 18, no. 1, pp. 79-99, 2015, doi: 10.1007/s10857-014-9274-7.

[18] L. Darragh, "Asking questions and performing mathematics identity," in Curriculum in focus: Research guided practice: Proceedings of the 37th Annual conference of the Mathematics Education Research Group of Australasia, 2014, no. 1968, pp. 175-182.

[19] M. Aziza, "An analysis of a teacher's questioning related to students' responses and mathematical creativity in an elementary school in the UK," Int. Electron. J. Elem. Educ., vol. 10, no. 4, pp. 475-487, 2018, doi: 10.26822/iejee.2018438138.

[20] A. Sahin and G. Kulm, "Sixth grade mathematics teachers' intentions and use of probing, guiding, and factual questions," J. Math. Teach. Educ., vol. 11, no. 3, pp. 221241, 2008, doi: 10.1007/s10857-008-9071-2.

[21] J. W. Creswell, Educational Research: Planning, Conducting and Evaluating Quantitative and Qualitative Research. Boston USA: Pearson Education, Inc, 2012.

[22] J. Ley, C. Attard, and K. Holmes, "The Five Question Approach : Disrupting the Linear Approach to Mathematics Teaching," in Making waves, opening spaces (Proceedings of the 41st annual conference of the Mathematics Education Research Group of Australasia), 2018, pp. 479-486.

[23] M. N. Browne and S. M. Keeley, Asking the Right Questions: A Guide to Critical Thinking, 11th ed. New Jersey: Pearson Education, Inc, 2015.

[24] M. N. Browne and S. M. Keeley, Asking the Right Questions: A Guide to Critical Thinking, 8th ed. New Jersey: Pearson Education, Inc., 2007. 